\title{
DUKUNGAN KELUARGA TENTANG TOILET TRAINING DENGAN KEBERHASILAN TOILETING PADA ANAK USIA 1 - 6 TAHUN DI PAUD AL HILAL KABUPATEN SUMENEP
}

\author{
Zakiyah Yasin, Program Studi Ilmu Keperawatan Universitas Wiraraja \\ email: zakiyahfik@wiraraja.ac.id \\ Nabela Alfina Aulia, Program Studi Ilmu Keperawatan Universitas Wiraraja \\ email: nabelaalfina21@gmail.com
}

\section{ABSTRACT}

In this era of globalization, parents can take care their toddler or pre - school children easily. Children at the toddler or pre - school age grow significantly. Parent supports is needed in guiding their children practicing the toilet training. Toilet training means children defecating and urinating control. Toilet training success is affected by parent knowledge, parents support, mother's job, the quality of mother's care, neighborhood and the availability of bathroom, soap, etc.

This research uses descriptive method with cross sectional design. At this research uses all population that 30 families and 1 till 6 years old - children recorded at PAUD AL Hilal Sumenep Regency. This research uses premiere data being obtained from questionnaire filled by respondents. This study aims to determine Family support about toilet training according to 1 till 6 years old children toileting success at PAUD Al Hilal Sumenep Regency.

The result show most of the respondents give good support (21 respondents or $70 \%)$ and most the respondent's children success in toileting (17 respondents or 56,67\%). The conclusion is most of the respondents give good support to the toileting success at PAUD Al Hilal Sumenep Regency. So do the children.

Respondent can increase the family support to their children by giving attention if their children had time to do toilet training.

Keywords: Family support, toilet training, toileting success

\section{PENDAHULUAN}

Anak merupakan penerus kehidupan bagi orang tuanya, sehingga anak harus mendapatkan perhatian khusus untuk dapat tumbuh dan berkembang sesuai dengan usianya. Tumbuh kembang pada anak merupakan proses yang berkesinambungan dari proses fertilisasi samapai usia dewasa (Soetjiningsih dkk, 2013). Lima tahun pertama selama anak berada di dunia merupakan masa emas (golden age) baginya. Pemenuhan kebutuhan dasar secara mandiri untuk dapat melaksanakan tugas-tugas perkembangan selanjutnya.

Pada era modernisasi ini, orang tua khususnya ibu sudah mulai mudah untuk merawat anaknya yang masih balita. Hal ini seiring dengan banyaknya produksi diapers untuk balita. Karena alasan praktis, banyak orang tua yang lebih memilih untuk memakaikan popok pada anaknya. Padahal cara ini akan menyulitkan proses belajar anak mengenai toilet training dan menghentikan kebiasaan mengompolnya. Sama seperti orang tuanya anak juga akan merasa lebih praktis dengan memakai popok dan tidak ingin untuk ke toilet (Novi, 2015).

Diapers atau popok modern ini banyak digunakan oleh para ibu untuk dapat memenuhi kebutuhan eliminasi (miksi dan defekasi) pada anaknya. Diapers merupakan popok sekali pakai yang dibuat dari plastik dan campuran bahan kimia yang mempunyai daya serap tinggi untuk menampung air seni dan feses (Diena,2009). Perlu diketahui bahwa penggunaan diapers dapat memperlambat keberhasilan toilet training.

Toilet training merupakan suatu usaha untuk melatih anak agar mampu mengontrol dalam melakukan buang air kecil dan buang 
air besar. Toilet training ini dapat berlangsung pada fase kehidupan anak yaitu usia 18-24 bulan (Hidayat, 2005). Keberhasilan toilet training dapat di nilai dari kesiapan diri anak dan keluarga yang mendukung anak untuk dapat mandiri.

Di Indonesia diperkirakan jumlah balita mencapai $30 \%$ dari 250 juta jiwa penduduk Indonesia dan menurut Survey Kesehatan Rumah Tangga (SKRT) diperkirrakan jumlah balita yang susah mengontrol BAB dan BAK (mengompol) diusia prasekolah mencapai 75 jua anak (Priyoto, 2015). Kejadian anak mengompol lebih besar pada anak laki-laki yaitu $60 \%$ dan anak perempuan $40 \%$. Statistik menunjukkan $25 \%$ anak mengompol pada usia 5 tahun akan menurun menjadi $5 \%$ pada usia 10 tahun dan tinggal 2\% pada usia 5-10 tahun (Kurniawati, 2008). Sebuah Survey yang pernah ada di Indonesia oleh tabloid Nakita menyebutkan setengah juta anak berusia 6-16 tahun masih suka mengompol, yang terdiri dari $17 \%$ anak berusia 5 tahun, $14 \%$ anak berusia 7 tahun, $9 \%$ anak berusia 9 tahu, dan 1-2\% anak berusia 15 tahun (Batuatas \& Tripeni, 2012).

Berdasarkan uraian diatas perlu diadakan penelitian dukungan keluarga tentang toilet training terhadap keberhasilan toileting pada anak usia 1 - 6 tahun di PAUD Al Hilal Kabupaten Sumenep. Hal tersebut perlu karena dapat dilakukan tindakan pencegahan dalam ketelambatan toileting yang akan berdampak pada anak usia sekolah seperti Enuresis (mengompol) dan Enkropesis (BAB sembarangan/ dicelana dalam).

\section{METODE PENELITIAN}

Metode penelitian ini menggunakan metode analitik deskriptif yaitu suatu metode penelitian yang dilakukan dengan tujuan utama untuk membuat gambaran tentang suatu keadaan secara objektif.

Penulis menggunakan rancang bangun cross sectional yaitu menekankan waktu pengukuran/observasi data variabel independent dan dependent hanya satu kali pada satu saat. Dengan kata lain penelitian yang dinilai secara simultan pada satu saat tanpa adanya tindak lanjut.

\section{HASIL PENELITIAN \\ Gambaran Umum Lokasi Penelitian}

PAUD Al Hilal merupakan salah satu PAUD yang berada di Kabupaten Sumenep. Pendidikan Anak Usia Dini atau sering disebut PAUD ini terletak di Jl. Imam Bonjol GG 1 RT 3 RW 1 Desa Pamolokan Kabupaten Sumenep. PAUD Al Hilal didirikan pada tahun 2010 dan hingga saat ini semakin berkembang menjadi PAUD yang lebih baik. PAUD ini memiliki 2 tingkatan yaitu PAUD itu sendiri dengan usia siswa 1 - 4 tahun dan TK dengan usia siswa $4-6$ tahun.

PAUD Al Hilal berada di perbatasan kota Sumenep dan dikelilingi oleh desa yang lain. Batas wilayah utara yaitu desa Kebunan, batas wilayah selatan yaitu desa Pangarangan, batas wilayah timur yaitu desa Bangkal dan batas wilayah barat yaitu desa Pajagalan. PAUD Al Hilal juga berdekatan dengan PAUD lain yaitu PAUD Palapa Ceria yang berjarak \pm 250 meter dari PAUD Al Hilal. Jumlah siswa yang tercatat di PAUD Al Hilal yaitu sebanyak 30 siswa dan bertempat tinggal di daerah desa Pamolokan Kabupaten Sumenep.

\section{Data Umum}

Tabel 1 Distribusi frekuensi usia orang tua di PAUD Al Hilal tahun 2018

\begin{tabular}{ccc}
\hline Usia & F & \% \\
\hline $17-25$ tahun & 3 & 10 \\
$26-35$ tahun & 20 & 66,7 \\
$36-45$ tahun & 6 & 20 \\
$46-55$ tahun & 1 & 3,3 \\
\hline Jumlah & 30 & 100 \\
\hline
\end{tabular}

Sumber data : Data Primer 2018

Tabel 2 Distribusi frekuensi riwayat pendidikan orang tua di PAUD Al Hilal tahun 2018

\begin{tabular}{ccc}
\hline Pendidikan & F & \% \\
\hline Tidak sekolah & 2 & 6,7 \\
SD & 3 & 10 \\
SMP & 3 & 10 \\
SMA & 2 & 40 \\
D3 & 2 & 6,67 \\
Sarjana (S1) & 8 & 26,67 \\
\hline Jumlah & 30 & 100 \\
\hline
\end{tabular}

Sumber data : Data Primer 2018 
Tabel 3 Distribusi frekuensi pekerjaan orang tua PAUD Al Hilal tahun 2018

\begin{tabular}{ccc}
\hline Pekerjaan & F & \% \\
\hline Bekerja & 10 & 33,3 \\
Tidak bekerja & 20 & 66,7 \\
\hline Jumlah & 30 & 100 \\
\hline
\end{tabular}

Sumber data : Data Primer 2018

Tabel 4 Distribusi frekuensi jumlah anak PAUD Al Hilal tahun 2018

\begin{tabular}{ccc}
\hline Jumlah anak & F & \% \\
\hline 1 anak & 3 & 10 \\
2 anak & 13 & 43,3 \\
$\geq 3$ anak & 14 & 46,7 \\
\hline Jumlah & 30 & 100 \\
\hline
\end{tabular}

Sumber data : Data Primer 2018

Tabel 5 Distribusi frekuensi jenis kelamin anak di PAUD Al Hilal tahun 2018

\begin{tabular}{ccc}
\hline Jenis Kelamin & F & \% \\
\hline Laki-laki & 14 & 46,7 \\
Perempuan & 16 & 53,3 \\
\hline Jumlah & 30 & 100
\end{tabular}

Sumber data : Data Primer 2018

Tabel 6 Distribusi frekuensi usia anak di PAUD Al Hilal tahun 2018

\begin{tabular}{ccc}
\hline Usia Anak & F & \% \\
\hline $1-3$ tahun & 12 & 40 \\
$4-6$ tahun & 18 & 60 \\
\hline Jumlah & 30 & 100 \\
\hline
\end{tabular}

Sumber data : Data Primer 2018

T'abel 7 Distribusi frekuensi tersedianya kamar mandi di rumah siswa PAUD Al Hilal tahun 2018

Tabel 11 Usia orang tua terhadap dukungan toilet training di PAUD Al Hilal tahun 2018

\begin{tabular}{ccccccccc}
\hline \multirow{2}{*}{$\begin{array}{c}\text { Usia Orang Tua } \\
\text { (Tahun) }\end{array}$} & \multicolumn{9}{c}{ Baik } & \multicolumn{9}{c}{ Cukup } & \multicolumn{1}{c}{ Kurang } & \multicolumn{3}{c}{ Total } \\
\cline { 2 - 10 } & $\mathbf{n}$ & $\mathbf{\%}$ & $\mathbf{n}$ & $\mathbf{\%}$ & $\mathbf{n}$ & $\mathbf{\%}$ & $\mathbf{n}$ & $\mathbf{\%}$ \\
\hline $\mathbf{1 7}-\mathbf{2 5}$ & 2 & 6,7 & 1 & 3,3 & - & - & 3 & 10 \\
$\mathbf{2 6}-\mathbf{3 5}$ & 14 & 46,7 & 6 & 20 & - & - & 20 & 66,7 \\
$\mathbf{3 6}-\mathbf{4 5}$ & 5 & 16,7 & 3 & 10 & - & - & 6 & 20 \\
$\mathbf{4 6}-\mathbf{5 5}$ & - & - & 1 & 3,33 & - & - & 1 & 3,3 \\
\hline Jumlah & 21 & 70 & 9 & 30 & - & - & 30 & 100 \\
\hline
\end{tabular}

Tabel 12 Pekerjaan orang tua terhadap dukungan toilet training di PAUD Al Hilal tahun 2018

\begin{tabular}{|c|c|c|c|c|c|c|c|c|}
\hline \multirow{3}{*}{$\begin{array}{l}\text { Pekerjaan } \\
\text { Orang Tua }\end{array}$} & \multicolumn{8}{|c|}{ Dukungan } \\
\hline & \multicolumn{2}{|c|}{ Baik } & \multirow{2}{*}{$\frac{\text { Cukup }}{n}$} & \multicolumn{3}{|c|}{ Kurang } & \multicolumn{2}{|c|}{ Total } \\
\hline & $\mathbf{n}$ & $\%$ & & $\%$ & $\mathbf{n}$ & $\%$ & $\mathbf{n}$ & $\%$ \\
\hline Bekerja & 6 & 20 & 4 & 13,3 & - & - & 10 & 33,3 \\
\hline Tidak Bekerja & 15 & 50 & 5 & 16,7 & - & - & 20 & 66,7 \\
\hline Jumlah & 21 & 70 & 9 & 30 & - & - & 30 & 100 \\
\hline
\end{tabular}

Tabel 13 Pendidikan orang tua terhadap dukungan toilet training di PAUD Al Hilal tahun 2018 


\begin{tabular}{|c|c|c|c|c|c|c|c|c|}
\hline \multirow{3}{*}{ Pendidikan Orang Tua } & \multicolumn{6}{|c|}{ Dukungan } & \multirow{2}{*}{\multicolumn{2}{|c|}{ Total }} \\
\hline & \multicolumn{2}{|c|}{ Baik } & \multicolumn{2}{|c|}{ Cukup } & \multicolumn{2}{|c|}{ Kurang } & & \\
\hline & $\mathbf{n}$ & $\%$ & $\mathbf{n}$ & $\%$ & $\mathbf{n}$ & $\%$ & $\mathbf{n}$ & $\%$ \\
\hline Tidak Sekolah & - & - & 2 & 0,7 & - & - & 2 & 0,7 \\
\hline SD & 1 & 0,3 & 2 & 0,7 & - & - & 3 & 0 \\
\hline SMP & 2 & .7 & 1 & 0,3 & - & - & 3 & 0 \\
\hline SMA & 11 & 6,7 & 1 & 0,3 & - & - & 12 & 0 \\
\hline D3 & 2 & 0,7 & - & - & - & - & 2 & 0,7 \\
\hline Sarjana & 5 & 6,7 & 3 & 10 & - & - & 8 & 6,7 \\
\hline Jumlah & 21 & 70 & 9 & 30 & - & - & 30 & 100 \\
\hline
\end{tabular}

Tabel 14 Jumlah Anak terhdap dukungan toilet training di PAUD Al Hilal tahun 2018

\begin{tabular}{|c|c|c|c|c|c|c|c|c|}
\hline \multirow[t]{3}{*}{ Jumlah Anak } & \multicolumn{6}{|c|}{ Dukungan } & \multirow{2}{*}{\multicolumn{2}{|c|}{ Total }} \\
\hline & \multicolumn{2}{|c|}{ Baik } & \multicolumn{2}{|c|}{ Cukup } & \multicolumn{2}{|c|}{ Kurang } & & \\
\hline & $\mathbf{n}$ & $\%$ & $\mathbf{n}$ & $\%$ & $\mathbf{n}$ & $\%$ & $\mathbf{n}$ & $\%$ \\
\hline 1 anak & 2 & 6,7 & 1 & 3,3 & - & - & 3 & 10 \\
\hline 2 anak & 9 & 30 & 4 & 13,3 & - & - & 13 & 43,3 \\
\hline$\geq 3$ anak & 10 & 33,3 & 4 & 13,3 & - & - & 14 & 46,7 \\
\hline Jumlah & 21 & 70 & 9 & 30 & - & - & 30 & 100 \\
\hline
\end{tabular}

Tabel 15 Usia orang anak terhadap keberhasilan toiletting di PAUD Al Hilal tahun 2018

\begin{tabular}{ccccccc} 
& \multicolumn{4}{c}{ Toiletting } & \multicolumn{2}{c}{ Total } \\
\cline { 2 - 6 } Usia Anak & \multicolumn{2}{c}{ Berhasil } & \multicolumn{2}{c}{ Tidak Berhasil } & & n \\
\cline { 2 - 6 } & $\mathbf{n}$ & $\mathbf{\%}$ & $\mathbf{n}$ & $\mathbf{\%}$ & $\mathbf{\%}$ \\
\hline Usia Toddler & 1 & 3,3 & 11 & 36,7 & 12 & 40 \\
Usia Pra Sekolah & 16 & 53,3 & 2 & 6,7 & 18 & 60 \\
\hline Jumlah & 17 & 56,7 & 13 & 43,3 & 30 & 100 \\
\hline
\end{tabular}

Tabel 16 Jenis kelamin anak terhadap keberhasilan toiletting di PAUD Al Hilal tahun 2018

Jenis Kelamin Anak Toiletting

Total

\begin{tabular}{ccccccc}
\cline { 2 - 7 } & $\mathbf{n}$ & $\mathbf{\%}$ & $\mathbf{n}$ & $\mathbf{\%}$ & $\mathbf{n}$ & $\mathbf{\%}$ \\
\hline Laki - laki & 8 & 26,7 & 6 & 20 & 14 & 46,7 \\
Perempuan & 9 & 30 & 7 & 23,3 & 16 & 53,3 \\
\hline Jumlah & 17 & 56,7 & 13 & 43,3 & 30 & 100 \\
\hline
\end{tabular}

Tabel 17 Usia orang tua terhadap keberhasilan toiletting di PAUD Al Hilal tahun 2018

\begin{tabular}{|c|c|c|c|c|c|c|}
\hline \multirow{3}{*}{ Usia Orang Tua } & \multicolumn{4}{|c|}{ Toiletting } & \multirow{2}{*}{\multicolumn{2}{|c|}{ Total }} \\
\hline & \multicolumn{2}{|c|}{ Berhasil } & \multicolumn{2}{|c|}{ Tidak Berhasil } & & \\
\hline & $\mathbf{n}$ & $\%$ & $\mathbf{n}$ & $\%$ & $\mathbf{n}$ & $\%$ \\
\hline $17-25$ & 2 & 6,7 & 1 & 3,3 & 3 & 10 \\
\hline $26-35$ & 10 & 33,3 & 10 & 33,3 & 20 & 66,7 \\
\hline $36-45$ & 5 & 16,7 & 1 & 3,3 & 6 & 20 \\
\hline $46-55$ & - & - & 1 & 3,3 & 1 & 3,3 \\
\hline Jumlah & 17 & 56,7 & 13 & 43,3 & 30 & 100 \\
\hline
\end{tabular}

Tabel 18 Pendidikan orang tua terhadap keberhasilan toiletting di PAUD Al Hilal tahun 2018 


\begin{tabular}{cccccccc}
\hline \multirow{2}{*}{ Pendidikan Orang Tua } & \multicolumn{4}{c}{ Toiletting } & \multicolumn{2}{c}{ Total } \\
\cline { 2 - 6 } & \multicolumn{2}{c}{ Berhasil } & \multicolumn{2}{c}{ Tidak Berhasil } & \multicolumn{2}{c}{} \\
\cline { 2 - 6 } & $\mathbf{n}$ & $\mathbf{\%}$ & $\mathbf{n}$ & $\mathbf{\%}$ & $\mathbf{n}$ & \% \\
\hline Tidak Sekolah & 1 & 3,3 & 1 & 3,3 & 2 & 6,7 \\
SD & 1 & 3,3 & 2 & 6,7 & 3 & 10 \\
SMP & 3 & 10 & 0 & 0 & 3 & 10 \\
SMA & 11 & 36,7 & 1 & 3,3 & 12 & 40 \\
D3 & 2 & 6,7 & - & - & 2 & 6,7 \\
Sarjana & 5 & 16,7 & 3 & 10 & 8 & 26,7 \\
\hline Jumlah & 17 & 56,67 & 13 & 43,33 & 30 & 100 \\
\hline
\end{tabular}

Tabel 19 Pekerjaan orang tua terhadap keberhasilan toileting di PAUD Al Hilal tahun 2018

\begin{tabular}{cccccccc}
\hline & \multicolumn{4}{c}{ Toiletting } & \multicolumn{3}{c}{ Total } \\
\cline { 2 - 6 } Pekerjaan Orang Tua & \multicolumn{2}{c}{ Berhasil } & \multicolumn{2}{c}{ Tidak Berhasil } & \multicolumn{2}{c}{} \\
\cline { 2 - 6 } & $\mathbf{n}$ & $\mathbf{\%}$ & $\mathbf{n}$ & $\mathbf{\%}$ & $\mathbf{n}$ & $\mathbf{\%}$ \\
\hline Bekerja & 4 & 13,3 & 6 & 20 & 10 & 33,3 \\
Tidak Bekerja & 13 & 43,3 & 7 & 23,3 & 20 & 66,7 \\
\hline Jumlah & 17 & 56,7 & 13 & 43,3 & 30 & 100 \\
\hline
\end{tabular}

Tabel 20 Jumlah anak terhadap keberhasilan toiletting di PAUD Al Hilal tahun 2018

\begin{tabular}{ccccccc}
\hline \multirow{2}{*}{ Jumlah Anak } & \multicolumn{3}{c}{ Toiletting } & \multicolumn{3}{c}{ Total } \\
\cline { 2 - 5 } & \multicolumn{2}{c}{ Berhasil } & Tidak Berhasil & & n \\
\hline 1 anak & $\mathbf{n}$ & $\mathbf{\%}$ & $\mathbf{\%}$ & 6,7 & 3 & $\mathbf{\%}$ \\
$\mathbf{2}$ anak & 1 & 26,7 & 16,7 & 13 & 43,3 \\
$\geq \mathbf{3}$ anak & 8 & 26,7 & 20 & 14 & 46,7
\end{tabular}

\section{PEMBAHASAN}

\section{Dukungan Keluarga}

Hasil penelitian menunjukkan bahwa sebagian besar responden menyatakan memberikan dukungan yang baik yaitu sebanyak 21 responden $(70 \%)$ dan sisanya menunjukkan dukungan orang tua yang cukup sebanyak 9 responden $(30 \%)$.

Ibu yang memberi dukungan kepada anaknya seperti mengantarkan anak jika ingin BAB dan BAK ke kamar mandi akan berhasil dalam toiletting. Semakin tinggi tingkat pendidikannya maka perilakunya juga akan semakin membaik. Dukungan optimal yang diberikan oleh orang tua akan mepengaruhi keberhasilan toileting. Menurut Supartini (2004) beberapa cara yang dapat dilakukan untuk dapat menjadi lebih siap dalam menjalankan peran adalah dengan terlibat aktif dalam setiap upaya pendidikan anak, mengamati segala sesuatu dengan berorientasi pada masalah anak.
Dukungan keluarga yang baik akan lebih memudahkan anak untuk melaksanakan toilet training dan tingkat keberhasilan toileting juga akan semakin besar. Toilet training seharusnya dapat dilaksanakan pada anak usia toddler (1-3 tahun). Kebanyakan balita memperlihatkan tanda-tanda kesiapan antara bulan ke $18-24$, tetapi beberapa balita siap lebih awal atau lebih dari 24 bulan (Pratiwi, 2017). Orang tua yang akan melatih anak untuk melakukan toilet training harus memiliki kesiapan fisik dan juga mental. Ibu yang sakit-sakitan juga akan memperlambat keberhasilan toilet training pada anak.

Hasil penelitian didapatkan usia orang tua yang mendukung dalam toilet training menunjukkan bahwa usia produktif yaitu usia 26 - 35 tahun memberi dukungan dalam kategori baik yaitu sebanyak 14 responden $(46,7 \%)$.

Hasil penelitian didapatkan sebagian besar tidak bekerja yaitu 15 responden $(50 \%)$ dan memberikan dukungan yang baik dalam 
keberhasilan toilet training. Menurut Supartini (2004) pekerjaan keluarga akan mempengaruhi peran orang tua karena waktu yang diberikan tidak maksimal, hal tersebut sesuai dengan yang terjadi ditempat penelitian di mana orang tua yang tidak bekerja cenderung berperan mendukung pada toilet training anak karena lebih mempunyai banyak waktu untuk melakukannya. Wanita karier akan lebih sulit dalam menerapkan toilet training secara dini karena waktu yang di berikan kepada anak cukup terbatas.

Hasil penelitian didapatkan hampir setengahnya orang tua (Ibu) berpendidikan SMA dan memberikan dukungan yang baik dalam keberhasilan toilet training yaitu sebanyak 11 responden $(36,7 \%)$. Hal ini sesuai dengan hasil penelitian yang dilakukan oleh Batuatas dkk, (2012) mengatakan bahwa responden yang berpendidikan lebih baik cenderung menunjukkan peran mendukung pada toilet training pada anak hal tersebut dikarenakan orang tua lebih siap dan mengetahui apa yang dibutuhkan oleh anak sehingga dapat memberikan dukungan yang lebih optimal pada anak dalam melakukan toilet training.

Semakin tinggi tingakat pengetahuan seseorang maka perilakunya juga akan semkin baik. Pendidikan orang tua anak menunjang dalam kerberhasilan toilet training. Hal ini dikarenakan orang yang berpendidikan tinggi akan lebih mudah paham terhadap sesuatu hal yang mungkin dapat memberikan dampak positif terhadap anak - anaknya. Orang tua yang berpendidikan tinggi juga akan lebih mudah paham jika toilet training tidak dilaksanakan sesuai dengan usianya akan mengakibatkan enuresis (mengompol) dan enkropresis (BAB di celana). Hal ini dapat terjadi pada anak usia pra sekolah maupun usia sekolah.

\section{Keberhasilan Toiletting}

Hasil penelitian menunjukkan bahwa sebagian besar anak responden berhasil dalam toiletting yaitu sebanyak 17 responden $(56,7$ $\%)$ dan sisanya menunjukkan tidak berhasil toiletting yaitu sebanyak 13 responden (43,3 $\%)$.

Toilet training merupakan cara untuk melatih anak agar bisa menahan buang air besar dan kecil sehingga bisa buang pada tempatnya yaitu toilet (Yulia, 2010). Toilet training (mengajarkan anak ke toilet) adalah cara anak untuk mengontrol kebiasaan buang hajatnya di tempat yang semestinya, sehingga tidak sembarangan membuang hajatnya (Ijs, 2010). Usia anak sekitar $18-30$ bulan umumpnya belum dapat untuk mengontrol $\mathrm{BAB}$ dan BAK karena masih belum menyadari fungsi tubuhnya. Anak tidak dalam situasi yang mungkin membuatnya tertekan (stres) seperti lahirnya adik, pindah rumah, ganti pengasuh dsb (Fitri, 2006).

Keberhasilan toiletting dapat dilihat dari kesiapan fisik, mental, psikologis dan prenatal anak. Kesiapan fisik, seperti anak dapat duduk, berjalan, dan berjongkok, Kesiapan mental, seperti anak dapat berkomunikasi untuk BAB atau BAK. Kesiapan psikologis yaitu anak mampu duduk di toilet selama 5-10 menit tanpa bergoyang atau terjatuh. Dan Kesiapan Prenatal yaitu anak berkeinginan untuk meluangkan waktu untuk toilet training (Novi, 2015)

Hasil penelitian didaptakan usia anak yang berhasil dalam toileting menunjukkan sebagian besar berusia pra sekolah dan berhasil dalam toileting yaitu sebanyak 16 responden $(53,3 \%)$. Keberhasilan toileting dapat dilihat dengan kriteria yang telah ditentukan oleh peneliti bahwa dikatakan berhasil dalam toileting jika anak tidak menggunakan diapers selama 24 jam. Keberhasilan menguasai tugas-tugas perkembangan (mulai belajar mengontrol buang air besar dan buang air kecil) pada usia toodler memerlukan bimbingan dari orang tua. Keberhasilan toilet training dapat dicapai apabila anak mampu mengenali keinginan untuk buang air besar atau buang air kecil, kemampuan fisik anak untuk mengontrol spinkter anal dan uretral akan dicapai pada usia anak 18-24 bulan (Whaley \& Wong, 2009).

Hasil penelitian didaptakan jenis kelamin anak yang berhasil dalam toileting menunjukkan hampir setengah berjenis kelamin perempuan dan berhasil dalam toileting yaitu sebanyak 9 responden $(30 \%)$. Anak laki-laki biasanya berbeda dengan anak perempuan, dimana anak perempuan cenderung lebih nurut mudah diatur apabila 
diperintah dibandingkan dengan anak laki laki yang lebih bandel begitu pula dalam perkembangannya anak laki-laki lebih meningkat pada setiap aspek perkembangan (Irawan dkk, 2012). Hal ini mungkin terjadi, jika anak perempuan yang lebih mudah untuk dilakukan toilet training. Karakteristik anak perempuan dan laki - laki berbeda. Anak laki - laki cenderung memiliki rasa ingin tahu yang tinggi sehingga sulit untuk diatur oleh orang tuanya. Sehingga para orang tua harus memiliki tenaga yang ekstra untuk merawat dan memberikan dukungan yang optimal terhadap keberhasilan toileting.

Hasil penelitian didaptakan usia orang tua yang berhasil dalam toileting hampir setengahnya berusia $26-35$ tahun yaitu sebanyak 10 responden (33,3\%). Dari jurnal penelitian yang dilakukan oleh Andriyani dkk (2014) mengemukakan bahwa usia 20 - 35 tahun merupakan usia dalam kategori subur. Usia subur akan mempengaruhi semangat ibu dalam melatih anak untuk melaukan toilet training. Usia ini juga merupakan usia yang cukup matang dalam memberikan latihan toilet training pada anak. Ibu yang terlalu tua akan mudah merasa lelah sehingga akan berakibat kegagalan pada toilet training.

Hasil penelitian didaptakan pendidikan orang tua yang berhasil dalam toileting menunjukkan hampir setengahnya berjenis lulusan SMA dan berhasil dalam toileting yaitu sebanyak 11 responden (36,7 \%). Pengetahuan berpengaruh pada penerapan toilet training pada anak. Ibu yang mempunyai tingkat pengetahuan yang baik, diharapkan pemahaman ibu baik tentang manfaat dan dampak dari toilet training, sehingga ibu akan mempunyai sikap yang positif terhadap toilet training (Munafiah, et al., 2013). Ibu yang memiliki tingkat pendidikan semakin tinggi akan lebih mengerti tentang kesehatan dan akan memberikan yang terbaik kepada anak dan keluarganya. Notoatmodjo (2010), yang menyatakan bahwa perilaku dipengaruhi oleh pengetahuan sebagai faktor predisposisi, jika pengetahuan baik diharapkan pada akhirnya prakteknya juga baik.

Hasil penelitian yang dilakukan didapatkan hampir setengahnya tidak bekerja yaitu 13 responden dan berhasilan toileting yaitu sebanyak (43,3\%). Menurut Suryabudhi
(2003) dalam Subagyo (2010) faktor yang mendukung keberhasilan toilet training yaitu Pekerjaan Ibu. Status pekerjaan ibu mempunyai hubungan yang bermakna dengan peneran toilet training secara dini pada anak usia toddler. Pekerjaan ibu dapat menyita waktu ibu untuk melatih anak melakukan toilet training secara dini sehingga akan berdampak pada terlambatnya anak untuk mandiri melakukan toilet training. Ibu yang tidak bekerja akan memiliki banyak waktu luang untuk memperhatikan tingkah laku anak. Ibu juga dapat memberikan latihan BAB dan BAK secara optimal tanpa adanya gangguan pada ibu. Ibu yang sibuk akan menghambat dalam keberhasilan toileting.

Hasil penelitian didaptakan jumlah anak yang berhasil dalam toileting menunjukkan hampir setengahnya memiliki 2 anak sebanyak 8 responden $(26,7 \%)$.

Hasil penelitian menunjukkan bahwa seluruhnya $100 \%$ anak di PAUD AL Hilal memiliki kamar mandi sendiri di rumahnya. Tersedianya fsilitas seperti jamban, handuk, air, gayung, sabun, kamar kecil (toilet) merupakan hal yang bisa mempengaruhi kelancaran latihan toilet training yang diberikan keluarga kepada anaknya (Subardja, 2005).

Kondisi lingkungan dengan masingmasing reponden memiliki kamar mandi di dalam di rumah memberi kemudahan kepada ibu-ibu untuk mengajarkan kepada anak dalam melakukan BAK atau BAB. Hasil penelitian yang pernah dilakukan oleh Herimanto (2012) mengemukakan faktor lingkungan sangat penting bagi kehidupan manusia karena lingkungan merupakan tempat hidup manusia, tumbuh dan berkembang, serta lingkungan juga memberikan sumber-sumber penghidupan manusia. Toilet training yang dilakukan di rumah diperlukan lingkungan yang aman, nyaman, dan yang memiliki estetika (Hoffnung dkk, 2010 dalam Fernandez, 2014). Selain itu, lingkungan fisik juga dapat dipengaruhi oleh faktor lingkungan sosial dan budaya mengenai rutinitas kebiasaan ke toilet.

Memiliki fasilitas seperti kamar mandi dapat mempermudah anak untuk melakukan toilet training secara dini. Hal ini juga menjadi salah satu faktor utama keberhasilan toilet training. Jika anak tidak memiliki kamar 
mandi sendiri dirumahnya akan membuat anak menjadi malas atau merasa tidak nyaman karena harus pergi ke sungai atau tempat lain yang bukan layaknya untuk BAB atau BAK. Orang tua harus juga memperhatikan kesipan anak dari segi fisik dan psikologis.

Hasil penelitian menunjukkan bahwa seluruhnya $100 \%$ anak di PAUD AL Hilal tidak memiliki gangguan pada fisik maupun mentalnya. Sehingga tingkat keberhasilan toileting masih cukup tinggi. Oleh karena itu, perkembangan anak yang optimal berperan penting dalam mengajarkan/melatih toilet training pada anak sehingga berhasil melakukan toileting dengan baik.

Anak yang memliki gangguan fisik dan mental tidak dapat diapaksa untuk melakukan toilet training sesuai dengan usia yang telah ditetapkan. Oleh Karena itu, ibu harus terus mendapingi anak sehingga ibu bisa tahu kapan anak dapat memulai latihan toilet training pada anak yang mengalami gangguan fisik dan mental.

\section{KESIMPULAN DAN SARAN Kesimpulan}

1. Sebagian besar responden memberi dukungan yang baik tentang toilet training terhadap keberhasilan toileting.

2. Sebagian besar anak responden berhasil dalam toileting.

\section{Saran}

1. Bagi peneliti selanjutnya

Dapat melakukan penelitian kepada responden yang lebih luas lagi, mengembangkan variabel - variabel yang belum diteliti, dan metode yang lebih lengkap untuk lebih menyempurnakan penelitian ini.

2. Bagi Profesi keperawatan

Diharapkan dapat dijadikan bahan rujukan untuk membentuk dan membina perawat agar memberikan promosi kesehatan mengenai toilet training, sehingga dapat mencegah penyakit - penyakit yang timbul akibat kegagalan toilet training.

3. Bagi institusi pendidikan keperawaran Meningkatkan peran instansi terkait serta perawat khsushnya keperawatan anak dalam melaksanakan promosi kesehatan, preventif khususnya toilet training. Dan mengembangkan variabel - variabel yang belum diteliti.

4. Bagi Institusi Pelayanan kesehatan

Meningkatkan peranan pelayanan kesehatan untuk memberikan promosi kesehatan mengenai manfaat dan dapak toilet training.

5. Bagi masyaraka

Bagi masyarakat khususnya ibu untuk selalu memperhatikan perkembangan dan pertumbuhan anak sehingga ibu dapat mengetahui kapan harus memulai toilet training.

\section{DAFTAR PUSTAKA}

Arikunto,S. (2005). Prosedur Penelitian Suatu Pendekatan Praktik. Jakarta: Rineka Cipta

Batuatas, R., \& Tripeni. (2012). Pengaruh Peran Ibu dengan Keberhasilan Toilet Trainning pada Anak Usia Toddler di Play Group Tarbiyatush Shibiyan Mojoanyar MojoKerto. Hospital Majapahit , 4, 70-82. http://ejurnalp2m.poltekkesmajapahit.a c.id/index.php/HM/article/viewFile/76 /66 Diakses pada tanggal 20 Desember 2017

Buston, E., \& Septiyanti. (2017, May). Hubungan Pendidikan Dan Sikap Dengan Keberhasilan Toilet Training. Mahakam Nursing Journal , 18-27.

Desiningrum, D. R. (2012). Buku Ajar Perkembangan Anak 1. Semarang.

Dislidel. (2011). Buku Ajar Asuhan Neonatus, Bayi \& Balita. Jakarta: EGC.

Effendy, N. (1998). Dasar-dasar Keperawatan Kesehatan Masyarakat (2 ed.). Jakarta: Buku Kedokteran EGC.

Fernandez, E. (2014). Early childhood: Dimensions and contexts of development and well-being. In Handbook of Child Well-Being (pp. 1629-1647). Springer Netherlands.

Frima, L. (2013). Gambaran pelaksanaan toilet training pada anak penyandang autisme. http://repository.unri.ac.id:80/handle/1 23456789/1888. Diakses pada 
tanggal 11 April 2018 pukul 14.00 WIB

Gilbert, J. 2006. Toilet Training: panduan melatih anak untuk mengatasi masalah toilet. Jakarta: Erlangga

Herimanto, W. (2012). Ilmu sosial \& budaya dasar. Jakarta: Bumi Aksara.

Hariwijaya, M., \& Sukaca, B. E. (2009). Melejitkan Potensi Anak dengan Pendidikan Sejak Dini. Yogyakarta: Mahadika Publishing.

Hidayat, A. A. (2005). Pengantar Ilmu Keperawatan Anak 1 (4 ed.). Jakarta: Salemba Medika.

Hooman, N. Safaii, A. Valavi, E. Alavijeh, A. (2013). Toilet Training in Iranian Children. Iran J. Pediart, April 2013. Vol. 3 No. 2. Pp : $154-158$.

Hurlock, E. B. (1978) Perkembangan Anak Jilid 2 (6 ed.). Jakarta: Erlangga.

Indanah, Azizah, N., \& Handayani, T. (2014). Pemakaian Diapers dan Efek terhadap Kemampuan Toilet Training pada Anak Usia Toddler. JIKK, 5, 61-68. http://ejr.stikesmuhkudus.ac.id/index.p hp/jikk/article/view/237 diakses pada tanggal 20 November 2017, pukul 20.00 WIB

Irawan, H., \& Dewi, I. (2013). Motivasi Ibu Tentang Toilet Training Pada Anak Usia 1-3 Tahun Di Wilayah Kerja Posyandu Dahlia Puskesmas Campurejo Kota Kediri.1.http://ejurnal.stikesbaptis.ac.id /index.php/keperawatan/article/view/1 82 diakses pada tanggal 20 November 2017, pukul 20.00 WIB

Irawan, R., \& Hasinuddin, M. (2012). Jurnal Nursing Update. Jurnal Ilmiah Ilmu Keperawatan 3 , 101106.http://www.nursingupdate.nhm .ac.id/files/ Volume-3-Nomor-2,Maret-2012.pdf diakses pada tanggal 18 Oktober 2017, pukul 14.00 WIB.

Istichomah, 2010. Hubungan tingkat pengetahuan ibu asuh dengan pelaksanaan toilet training secara mandiri pada anak usia toddler di TPA Citra RSU Rajawali Citra Bantul. Diakses pada tanggal 23 Mei 2018, pukul 08.00 WIB
Lestari, Puji. 2013, Hubungan antara tingkat pengetahuan ibu tentang toilet training dengan praktik ibu dalam penggunaan diapers pada anak usia toddler (1-3 tahun) di kelurahan Putat Purwodadi tahun 2013. Diakses pada tanggal 11 Mei 2018, Pukul 09.00 WIB

Listyanti, Agita Sukma. 2012, Beri Toilet Training, Hilangkan Ketergantungan Anak pada Popok. http ://m. suiuasurabalza.net/kel anakota/. Diakses pada tanggal 11 Mei, Pukul $09.00 \mathrm{WIB}$

Maramis, W. F. (2006). Perilaku Dalam Pelayanan Kesehatan. Surabaya: Airlangga University Press. http://repository.unusa.ac.id/352/ diakses pada tanggal $20 \quad$ Oktober 2017, pukul 15.00 WIB

McMorris. (2013). Family and Staff Perspective on Service Use for Individuals with Intellectual Disabilities in Crisis. Journal of Mental Health Research in Intellectual Disabilities, 6:1, 14 -28.

Millei, Z., \& Gallagher, J. (2012). Opening spaces for dialogue and re-envisioning children's bathroom in a preschool: Practitioner research with children on a sensitive and neglected area of concern. International Journal of Early Childhood, 44(1), 9-29.

Nirwana. (2011). Psikologi Bayi, Balita, dan Anak . Yogyakarta: Nuha Medika.

Notoatmodjo, S. (2010). Promosi Kesehatan dan Ilmu Perilaku. Jakarta. Rineka Cipta.

Novi, B. (2015). Diberi Hadiah atau Dihukum. Yogyakarta: Saufa.

Novi, B. (2015). Kebiasaan-kebiasaan Buruk Sehari-hari (Vol. 1). (Hira, Ed.) Yogyakarta: FlashBooks.

Novi, B. (2015). Tanya Jawab Seputar Parenting. Yogyakarta: FlashBooks.

Nursalam. (2014). Metodologi Penelitian Ilmu Keperawatan (4 ed.). Jakarta: Salemba Medika.

Perry \& Potter. 2005. Buku Ajar Fundamental Keperawatan Konsep, Proses dan Praktik. Edisi kedelapan. Jakarta: EGC 
Partini.2010. Pengantar Pendidikan Anak Usia Dini. Grafindo Litera Media; Yogyakarta

Priyoto. (2015). Perubahan dalam Perilaku Kesehatan. Yogyakarta: Graha Ilmu.

Ratne. (2016). Hubungan Pola Asuh Orang Tua dengan Keberhasilan Toilet Training pada anak usia Toddler di desa Nyatnyono Kecamatan Ungaran Barat Kabupaten Semarang. Diakses pada tanggal $11 \quad$ Mei 2018, Pukul 09.00 WIB

Riblat. 2003. Tanda-tanda kesiapan anak dalam toilet training. $\mathrm{http} / /$ : www.medicastro.com. Diakses tgl 18 Desember 2017

Rirismawati, (2010). Hubungan antara tingkat pengetahuan ibu tentang toilet training dengan kemampuan anak mengontrol BAK dan BAB di PAUD Melati Kedaung Kaliangke Cengkareng Jakarta Barat 2010. http://Library.esaunggul.ac.id/opac/info pustaka4.php.id. Diakses pada tanggal 3 April 2018

Setiadi. (2008). Konsep \& Proses Keperawatan Keluarga. Yogyakarta: Graha Ilmu.

Setiadi. (2013). Konsep dan Praktik Penulisan Riset Keperawatan (2 ed.). Yogyakarta: Graha Ilmu.

Soetjaningsih. (2012). Pembuahan Anak Sejak Pembuahan Dengan Kanak-kanak Akhir. Jakarta: Prenada Media Group.

Soetjiningsih, Ranuh, I. G., \& Suyono, Y. J. (2013). Tumbuh Kembang Anak (2nd ed.). Jakarta: EGC.

Subagyo, A. S., \& Siti, W. (2010). Hubungan antara motivasi stimulasi toilet training oleh ibu dengan keberhasilan toilet training pada anak prasekolah. Jurnal Penelitian Kesehatan Suara Forikes.121013616140.pdf. Diakses pada tanggal 23 November 2017

Supartini. Yupi. 2004. Buku Ajar Konsep Keperawatan Anak. Jakarta. EGC

Wahyudi, A. S., \& Wahid, A. (2016). Ilmu Keperawatan Dasar. Jakarta: Mitra Wacana Media.

Warlenda, S. V., \& Sari, R. N. (2017). Pengetahuan Ibu Berhubungan dengan Pelaksanaan Toilet TrainingPada Anak
Usia 3-5 tahun di PAUD Islam Cerliana Kota Pekanbaru Tahun 2016. Junal Kesehatan Komunitas , 105-109.

Warner, P. (2007). Mengajak Anak Pergi Toilet. Jakarta: Arean.

Wong. 2000. Pedoman Klinis Keperawatan Pediatrik, jakarta: EGC

Yanuarita, F. A. (2014). Rahasia Otak dan Kecerdasan Anak. Yogyakarta: Teranova Books. 
